FORSCHUNGSBERICHTE DES LANDES NORDRHEIN-WESTFALEN

Nr. 1640

Herausgegeben

im Auftrage des Ministerpräsidenten Dr. Franz Meyers

von Staatssekretär Professor Dr. h. c. Dr. E. h. Leo Brandt 
DK 539.183.2:539.128.412

\section{Gisela Kauw}

Institut für Strablen-und Kernpbysik der Universität Bonn

Direktor: Prof. Dr. Wolfoang Riezler †

\section{Untersuchungen an angereicherten Isotopen auf natürliche Alphastrahlung}

W

SPRINGER FACHMEDIEN WEISBADEN GMBH 1966 
ISBN 978-3-663-06490-9 ISBN 978-3-663-07403-8 (eBook)

DOI 10.1007/978-3-663-07403-8

Verlags-Nr. 011640

(C) 1966 by Springer Fachmedien Wiesbaden

Ursprünglich erschienin bei Westdeutscher Verlag, Köln und Opladen 1966 
Inhalt

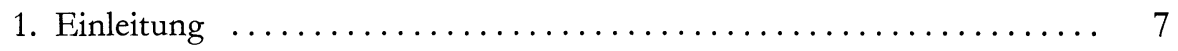

2. Nachweismethode und Verfahrenstechnik .................. 8

3. Untersuchungsergebnisse $\ldots \ldots \ldots \ldots \ldots \ldots \ldots \ldots \ldots \ldots \ldots \ldots \ldots \ldots \ldots \ldots, 12$

4. Zusammenfassung $\ldots \ldots \ldots \ldots \ldots \ldots \ldots \ldots \ldots \ldots \ldots \ldots \ldots \ldots \ldots \ldots \ldots \ldots \ldots \ldots \ldots, 25$

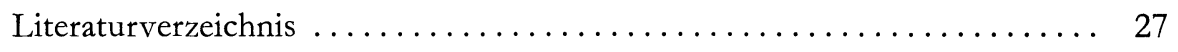

